\title{
Progesterone therapy attenuates fetal brain cytokine levels and improves survival/birth weights in infected rat pups
}

\author{
Christian M. Briery ${ }^{1}$, Carl H. Rose ${ }^{2}$, Kedra Wallace ${ }^{3}$, William A. Bennett ${ }^{3}$, Rick W. Martin ${ }^{3}$ and John C. Morrison ${ }^{3 *}$ \\ ${ }^{1}$ Departments of Obstetrics and Gynecology Division of Maternal-Fetal Medicine, Willis Knighton Medical Center, Shreveport, LA, USA \\ ${ }^{2}$ Division of Maternal-Fetal Medicine, Department of Pathology, The Mayo Clinic, Rochester, MN, USA \\ ${ }^{3}$ Department of Obstetrics and Gynecology, University of Mississippi Medical Center, Jackson, Mississippi, USA
}

\begin{abstract}
The study was designed to test the hypothesis that progesterone attenuates the fetal inflammatory response to infection. Timed-pregnant (Day 17$)$ Sprague Dawley rats were randomly assigned to the following treatment groups: 1$)$ growth media negative-control, 2) E. coli inoculated $\left(1 \times 10^{7} \mathrm{CFU}\right)$ positive-control, 3$) \mathrm{E}$. coli + Ceftriaxone $(20 \mathrm{mg} / \mathrm{kg} /$ day $), 4)$ E. coli + Ceftriaxone + Progesterone (50 mg/kg/day), 5) E. coli + Progesterone. Pup survival data and birth weights were recorded, and brains were assessed for tissue levels of TNF- $\alpha$ and IL-1 $\beta$. When compared to the positive control group, the progesterone/antibiotic or progesterone only therapy (Group 4-5) improved pup survival rates. $(\mathrm{p}=.001)$, live birth weights ( $\mathrm{p}=.001)$, and resulted in decreased levels of fetal brain cytokines (TNF $\alpha$, $\mathrm{p}=.001$, .01 - Groups 4-5), (IL-1 $\beta, \mathrm{p}=.001, .01$ - Group 4-5). Also when E. coli + antibiotic treatment (Group 3) was compared to Groups 4 and 5 pup survival and birth weight was improved $(\mathrm{p}=.001)$ as was cytokine expression. Progesterone treatment was effective in improving survival rates and live birth weights in pups born to experimentally infected dams. Progesterone may provide protection from infection mediated neurologic damage from the inflammatory cytokines IL-1 $\beta$ and TNF- $\alpha$.
\end{abstract}

\section{Introduction}

In the United States, the incidence of preterm birth remains over $11 \%$ and is one of the most common medical complications of pregnancy [1]. In addition, prematurity is still the leading cause of perinatal mortality and accounts for $>75 \%$ of neonatal morbidity [2]. All sources agree that 17 -alpha hydroxy progesterone caporate $(17 \mathrm{P})$ is recommended for the treatment of patients with a singleton pregnancy and history of prior spontaneous preterm birth as weekly maternal injections from 20-34 weeks gestation in those patients with prior spontaneous preterm birth, which leads to a significant decline in the rate of an early delivery as well as an increase in birth weight among treated subjects [3].

While there are many causes of preterm births, it is believed that many spontaneous deliveries prior to 32 weeks are associated with infection [4]. The role of cytokines as an initiator of preterm labor is well described and proinflammatory cytokines are elevated in women with infection [5,6]. Furthermore, articles regarding Fetal Inflammatory Response Syndrome (FIRS) have confirmed the relationship between elevated proinflammatory cytokines and cerebral palsy as well as neonatal brain injury $[7,8]$. FIRS occurs, in most cases, without evidence of neonatal infection, but the labor process is often associated with proinflammatory cytokines, which suggest a linkage between preterm labor, inflammatory cytokines and many neonatal complications associated with preterm delivery [9]. Progesterone has been shown to have a suppressive effect on the inflammatory response and cytokine production [10].

The purpose of this study was to investigate, in the rat model, the effect of progesterone on brain cytokine production in infected and non-infected pregnant rats.

\section{Materials and methods}

Approval was obtained from the animal compliance office and the University of Mississippi Medical Center Institutional Review Board for this study. The University's Institutional Animal Care and Use Committee (IACUC) also approved all experimental procedures prior to their initiation. Forty-four timed-pregnant Sprague Dawley rats were purchased from Harlan Sprague Dawley (Indianapolis, IN). After arrival animals had similar light/dark time periods and access to food/water ad lib. All rats were allowed 4 days to stabilize before the experimental procedures were carried out. Animals were randomly assigned to one of the following treatment groups: 1) Growth media(negative control), 2) E. coli-(positive control $\left.\left.1 \times 10^{7} \mathrm{CFU}\right) 3\right) \mathrm{E} . \mathrm{coli}+$ Ceftriaxone (20 mg/kg/day) 4) E. coli + Ceftriaxone + Progesterone (50 $\mu \mathrm{g} / \mathrm{kg} /$ day), 5) E. coli + Progesterone. The dose of progesterone was selected as it approximates that used in the human gestation.

On gestational day 17 all dams underwent midline laparotomy with general anesthesia using $5 \%$ isoflurane. The uterus was exteriorized and the total number of pups were counted and recorded. Either $0.1 \mathrm{~mL}$ of broth (negative control-Group 1) or $0.1 \mathrm{~mL}\left(1 \times 10^{7} \mathrm{CFU}\right)$ of $E$. coli, (positive control-Group 2) was injected into the bifurcation on the uterine horn. In Groups 3 through 5, E. coli was also injected during the operative procedure in a similar fashion. After the procedure was complete the incision was closed using a continuous running stitch with delayed absorbable suture after the uterus was returned to its anatomical position. Animals randomized to the progesterone arms of

Correspondence to: John C. Morrison, Department of Obstetrics and Gynecology, University of Mississippi Medical Center 2500 North State Street, Jackson, MS 39216-4505, USA;E-mail: jmorrison@umc.edu

Received: May 20, 2015; Accepted: June 07, 2015; Published: June 13, 2015 
the study (Group 4 and 5) had a pre-primed and loaded mini-osmotic pump (Alzet minipump \#1007D, DURECT Corporation, Cupertino CA) implanted subcutaneously. A sialastic catheter was attached to the pump and ported into the peritoneal cavity for delivery of progesterone total $(50 \mathrm{mg} / \mathrm{kg} /$ day). Animals in groups 3 and 4 received daily antibiotic injections $(20 \mathrm{mg} / \mathrm{kg})$ until delivery.

Post treatment, dams were observed twice daily by the investigators. The number of live pups per litter and their birth weights was recorded for each treatment group. On postnatal day 2, three pups per litter were randomly selected and sacrificed. Brains were removed and placed in $10 \mathrm{ml}$ 's of cold PBS for homogenization. Brain homogenates were held at $-8^{\circ} \mathrm{C}$ until analysis. Enzyme-linked immunosorbent assay (ELISA) was used to determine the concentrations of IL- $1 \beta$ and TNF- $\alpha$ using cytokine-specific kits (eBioscience, San Diego, CA). Brain homogenates were also subjected to Lowery protein analysis, and cytokine values were corrected and expressed as picogram of cytokine/mg of protein.

Data was normally distributed and expressed as mean \pm standard deviation (SD). Statistical analysis was performed using Sigma Plot for Windows version 13.0 (Systal Software, Inc. San Jose, California). When appropriate a two-tailed t-test and one-way ANOVA was used. A probability level of $<0.05$ was considered statistically significant.

\section{Results}

Forty-four pregnant dams were used during the course of the study in order to achieve statistical power. Table 1 lists pup survival rates born to treated dams in the five respective treatment groups. The highest pup survival rates, compared to the infected controls (Group 2) were found in dams receiving either progesterone alone or in combination with antibiotics ( $\mathrm{p}<.001$, Groups 4, 5). Antibiotics alone also improved pup survival rates when compared to positive controls $(52 \%, \mathrm{p}=.007)$. As expected, pups born to infected dams in Group 2 (positive controls) did poorly with a survival rate of $34 \%$ which was significantly lower than negative controls $(97 \%, \mathrm{p}<.001)$. Experimentally infected dams receiving either progesterone alone or in combination with antibiotics had survival rates not different from Group 1 negative controls (83\%, $\mathrm{p}=.096$ ). Progesterone treatment (Groups 4,5 ) was also significantly better than antibiotics alone (Group 3) survival rates ( $\mathrm{p}<.001)$.

Table 1 also shows the birth weights found in each group. E. coli alone (Group 2) resulted in a significant reduction in live birth weight $(5.70 \pm 0.11 \mathrm{~g} v$ s. $4.98 \pm 0.14 \mathrm{~g}, \mathrm{p}<.001)$ when compared to negative controls. Antibiotics alone did not significantly increase live birth weights in pups born to infected dams $(5.03 \pm 0.16, \mathrm{p}=.554)$ whereas addition of progesterone, with or without antibiotics, significantly improved birth weights $(5.72 \pm 0.14$ - Group 4, $5.48 \pm 0.14$ - Group 5) compared to pups born to experimentally infected dams (Group 2, $\mathrm{p}=.001)$.

Figure 1 describes the cytokine assays results for Tumor Necrosis

Table 1. Litter birth weight \& survival data from experimentally infected dams

\begin{tabular}{|c|c|c|c|c|c|}
\hline & $\begin{array}{c}\text { Group 1 } \\
\text { Negative } \\
\text { Controls } \\
\text { (Broth) } \\
N=5\end{array}$ & $\begin{array}{c}\text { Group } 2 \\
\text { Positive } \\
\text { Controls } \\
\text { (E. coli) } \\
\quad N=6\end{array}$ & $\begin{array}{c}\text { Group } 3 \\
\text { E. coli }+A B^{o} \\
N=8\end{array}$ & $\begin{array}{c}\text { Group 4 } \\
\text { E. Coli }+A B+P^{X} \\
N=8\end{array}$ & $\begin{array}{c}\text { Group } 5 \\
\text { E. Coli }+P^{X} \\
N=5\end{array}$ \\
\hline Survival & $96.7 \pm 1.2$ & $33.8 \pm 12.3$ & $52.3 \pm 8.9$ & $83.2 \pm 14.5$ & $82.2 \pm 10.3$ \\
\hline $\begin{array}{l}\text { Pup Birth } \\
\text { Weight (grams) }\end{array}$ & $5.70 \pm 0.11$ & $4.98 \pm 0.14$ & $5.03 \pm 0.16$ & $5.72 \pm 0.14$ & $5.48 \pm 0.16$ \\
\hline
\end{tabular}

${ }^{0} \mathrm{AB}=$ Antibiotic, ${ }^{\mathrm{x}} \mathrm{P}=$ Progesterone
TNFalpha

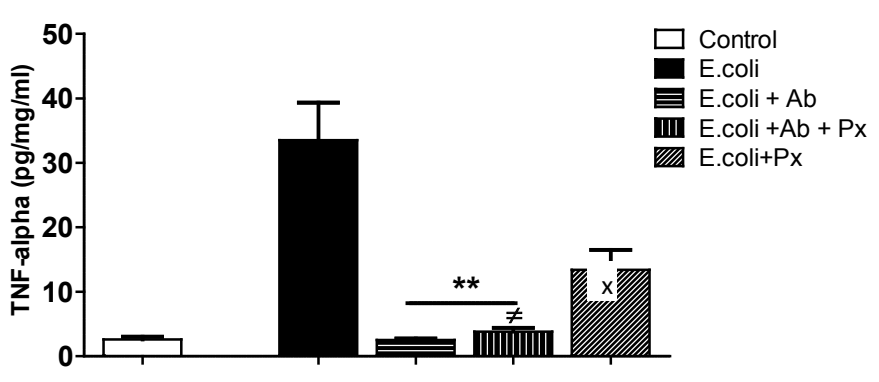

${ }^{* *}$ Gp 3, 4 vs Gp 2. $=.001 \quad{ }^{\mathrm{x}}$ Gp 5 vs Gp 2, $=.01$
$\neq$ Gp 4 vs Gp 3, p=.001

IL-1Beta

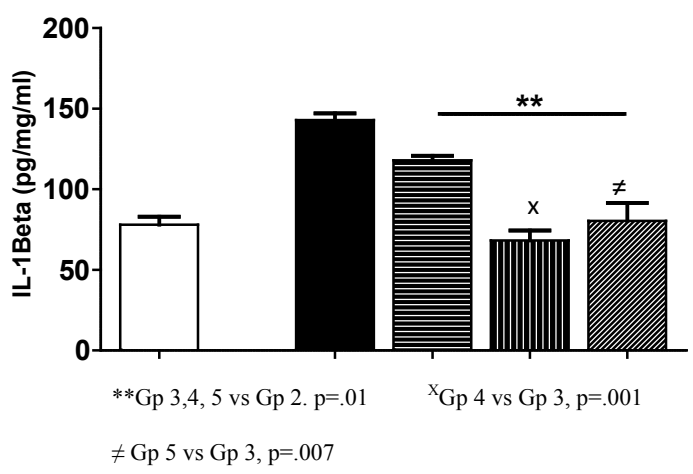

Figure 1. TNF $\alpha$ and IL-1 $\beta$ Results.

Factor $\alpha$ (TNF- $\alpha$ ) and Interleukin-1 beta (IL-1 $\beta$ ) in brain homogenates of rat offspring per $\mathrm{pg} / \mathrm{mg}$ protein. Treated pups receiving E. coli (positive control) had a significantly higher levels of TNF- $\alpha$ in brain specimens compared to the negative controls $(2.6 \pm 1.0$ vs. $33.5 \pm$ $14.3, \mathrm{p}<.001)$. Therapy with antibiotics alone and antibiotics with progesterone (Groups 3,4) had significantly lower TNF- $\alpha$ values than positive controls with $E$. coli infection ( $<<.001)$. Progesterone therapy without antibiotic (Group 5) also significantly reduced neonatal brain levels of TNF- $\alpha(13.4 \pm 6.9, p<.01)$ in pups born to infected dams. A difference was seen in treatment Group 4 TNF- $\alpha$ levels when compared to antibiotics alone (Group 3) $\mathrm{p}<.001$, however, progesterone alone (Group 5) did not show a difference when compared to antibiotics alone.

Interleukin -1 beta (IL-1 $\beta$ ) levels were significantly higher in the E. coli only group $(143 \pm 10.0)$ compared to negative controls $(78 \pm$ $11.0, \mathrm{p}<.001)$. All treatments groups showed a significant reduction in the IL- $1 \beta$ in pup brain homogenates when compared to the positive control $(\mathrm{p}<.01)$. A significant difference was seen in IL- $1 \beta$ levels when Group $4(68.2 \pm 17.7, \mathrm{p}<.001)$ and $5(80.4 \pm 25, \mathrm{p}<.007)$ were compared to Group 3(118 \pm 18$)$.

\section{Discussion}

Progesterone has immunosuppressive properties that are thought to contribute to the immune privilege afforded the fetal allograft during successful pregnancy [11]. This results in a moderate suppression of cell-mediated immunity while leaving the humoral immune response 
intact. Progesterone is thought to induce suppression via the induction of a protein in peripheral blood lymphocytes that shifts the expression of cytokines produced by $\mathrm{T}$-helper cells from a proinflammatory (TH1) to an anti-inflammatory (TH-2) pattern of expression [12]. We hypothesize that progesterone therapy could dampen both maternal and fetal immune responses to intrauterine infection and in turn restore the cytokine balance via attenuation of fetal cytokine expression.

The results of this study confirm that combined antibiotics and progesterone or progesterone alone improves survival as well as birth weights in pup born to infected dams. Elovitz et al. reported that medroxprogesterone acetate (MPA) preserved fetal viability and prevented inflammation-induced preterm parturition in mice in response to streptococcal infection [13]. Progesterone also appears to reduce the expression of multiple cytokines including, TNF- $\alpha$ and IL- $1 \beta$, in the rat models involving infection mediated brain injury and hypoxic lesions $[14,15]$. The concept of progesterone acting to dampen the fetal inflammatory immune response was confirmed by the reduction in IL-1 $\beta$ levels seen in pups born to infected dams. The induction of proinflammatory cytokines has been proposed as a link between prenatal maternal intrauterine infection and neonatal brain damage. This was illustrated by Cai et al. who reported large increase in the expression of brain IL-1 $\beta$ mRNA shortly after injection of LPS [16]. High concentrations of TNF- $\alpha$ and IL- $1 \beta$ have been shown to predict cerebral lesions detected by magnetic resonance imaging soon after delivery [17].

In summary, progesterone with or without antibiotics appears to improve survival and birth weight as well as modulate inflammatory cytokines expression in the brain homogenates of rat pups born to infected dams. Future investigations should focus on expanding the study to a larger group of animal subjects and to evaluate the effects of different dosages and types of progesterone in preventing of brain injury in pups exposed to in-utero infection.

\section{References}

1. Hamilton BE, Martin JA, Ventura SJ (2013) Births: preliminary data for 2011. Natl Vital Stat Rep 62: 1-90. [Crossref]

2. Klauser CK, Briery CM, Keiser SD, Martin RW, et al. (2012) Effect of antenatal tocolysis on neonatal outcomes. J Matern Fetal Neonatal Med 25: 2778 - 81. [Crossref]
3. Berghella V (2012) Progesterone and preterm birth prevention: translating clinical trials data into clinical practice. AM J Obstet Gynecol 376-86. [Crossref]

4. ACOG. Chorioamniontis and Intrapartum Fever. Neonatal Encephalopathy and Neurologic Outcome. 2nd edition. Chapter 6: 92-94

5. Romero R, Erez O, Espinoza J (2005) Intrauterine Infection, Preterm labor and cytokines. J Soc Gynecol Investig 12: 463-475 [Crossref]

6. Grether JK, Nelson KB (2000) Maternal infection and cerebral palsy in infants of normal birth weight. JAMA 278: 207-11. [Crossref]

7. Wu YW, Escobar GJ, Grether JK, Croen LA, Greene JD, et al. (2003) Chorioamnionitis and cerebral palsy in term and near-term infants. JAMA 290: 2677-84. [Crossref]

8. Mittendorf R, Montag AG, MacMillan W, Janeczek S, Pryde PG et al. (2003) Components of the systemic fetal inflammatory response syndrome as predictors of impaired neurologic outcomes in children. AM J Obstet Gynecol 118: 1438-46. [Crossref]

9. Gaudet LM, Smith GN (2001) Cerebral palsy and chorioamnionitis: the inflammatory cytokine link. OB/Gyn Survey 56: 433-36. [Crossref]

10. Zachariades E, Mparmpakas D, Pang Y, Rad-Weaver M, Thomas P, et al. (2012) Changes in placenta progesterone receptors in term and preterm labor. Placenta 33: 367-372.[Crossref]

11. Tan IJ, Peeva E, Zandman-Godard G (2015) Hormonal modulation of the immune system - a spot on the role of progestogens. Autoimmunity Reviews 14: 536-542. [Crossref]

12. Peltier MR, Tee SC, Smulian JC (2008) Effect of progesterone in proinflammatory cytokine production by monocytes stimulated with pathogens associated with preterm birth. Am J Repro Immunol 346-353. [Crossref]

13. Elovitz M, Wang Z (2004) Medroxyprogesterone acetate, but not progesterone, protects against inflammation-induced parturition and intrauterine fetal demise. Am J Obstet Gynecol 190: 693-701. [Crossref]

14. Lei B, Mace B, Dawson HN, Warner DS, Laskowitz DT, et al. (2014) Anti-inflammatory effects of progesterone in lipopolysaccharide-stimulated BV-2 microglia. PLoS One 9: e103969. [Crossref]

15. Wang X, Zhang J, Si D, Shi R, Dong W, et al. (2013) Progesterone inhibits the expression of cycloxygenase- 2 and interleukin- $1 \beta$ in neonatal rats with hypoxic ischemic brain damage. Int $J$ Neurosci 124: 42-8. [Crossref]

16. Cai Z, Pan ZL, Pang Y, Evans OB, Rhodes PG (2000) Cytokine induction in fetal rat brains and brain injury in neonatal rats after maternal lipopolysaccharide administration. Pediatr Res 47: 64-72. [Crossref]

17. Duggan PJ, Maalouf EF, Watts TL, Sullivan MH, Counsell SJ, et al. (2001) Intrauterine T-cell activation and increased proinflammatory cytokine concentrations in preterm infants with cerebral lesions. Lancet 358: 1699-700. [Crossref]

Copyright: $\odot 2015$ Briery CM. This is an open-access article distributed under the terms of the Creative Commons Attribution License, which permits unrestricted use, distribution, and reproduction in any medium, provided the original author and source are credited. 